PREPARED FOR THE U.S. DEPARTMENT OF ENERGY, UNDER CONTRACT DE-AC02-76CH03073

PPPL-3999

PPPL-3999

UC-70

Marginal Stability of Microturbulence

near ITB Onset on Alcator C-Mod

by

J.A. Baumgaertel, M.H. Redi, R.V. Budny,

D.C. McCune, W. Dorland, and C.L. Fiore

August 2004

NM|

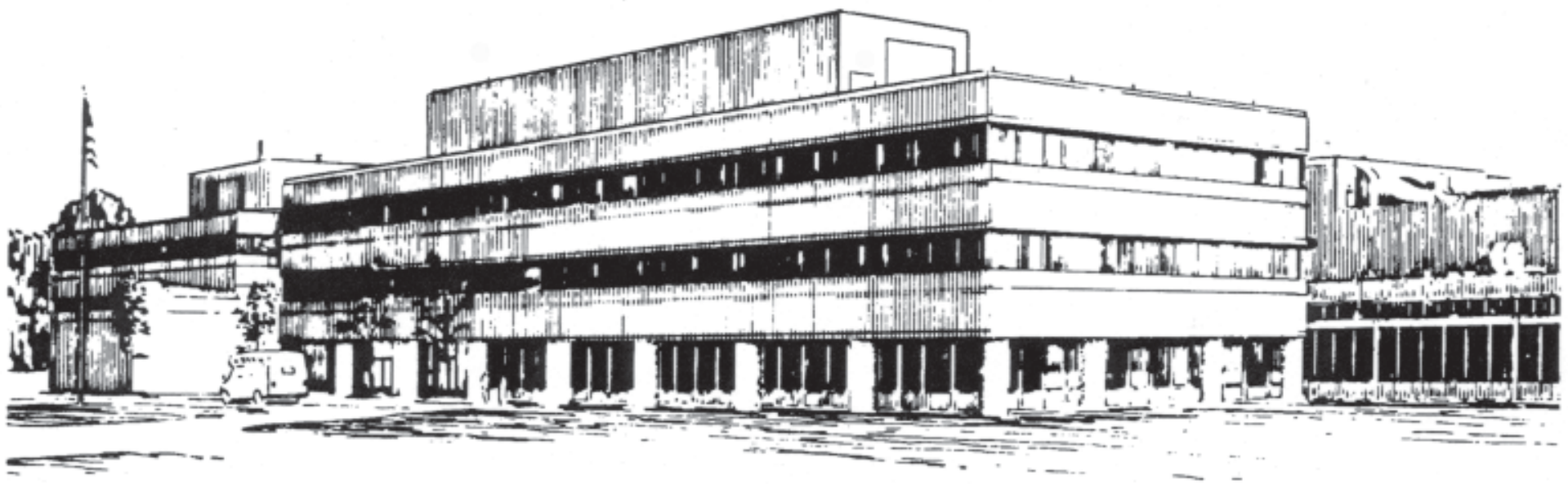

PRINCETON PLASMA PHYSICS LABORATORY PRINCETON UNIVERSITY, PRINCETON, NEW JERSEY 


\section{PPPL Reports Disclaimer}

This report was prepared as an account of work sponsored by an agency of the United States Government. Neither the United States Government nor any agency thereof, nor any of their employees, makes any warranty, express or implied, or assumes any legal liability or responsibility for the accuracy, completeness, or usefulness of any information, apparatus, product, or process disclosed, or represents that its use would not infringe privately owned rights. Reference herein to any specific commercial product, process, or service by trade name, trademark, manufacturer, or otherwise, does not necessarily constitute or imply its endorsement, recommendation, or favoring by the United States Government or any agency thereof. The views and opinions of authors expressed herein do not necessarily state or reflect those of the United States Government or any agency thereof.

\section{Availability}

This report is posted on the U.S. Department of Energy's Princeton Plasma Physics Laboratory Publications and Reports web site in Fiscal Year 2004. The home page for PPPL Reports and Publications is: http://www.pppl.gov/pub_report/

DOE and DOE Contractors can obtain copies of this report from:

U.S. Department of Energy

Office of Scientific and Technical Information

DOE Technical Information Services (DTIS)

P.O. Box 62

Oak Ridge, TN 37831

Telephone: (865) 576-8401

Fax: (865) 576-5728

Email: reports@adonis.osti.gov

This report is available to the general public from:

National Technical Information Service

U.S. Department of Commerce

5285 Port Royal Road

Springfield, VA 22161

Telephone: $1-800-553-6847$ or

(703) $605-6000$

Fax: (703) 321-8547

Internet: http://www.ntis.gov/ordering.htm 


\title{
Marginal stability of microturbulence near ITB onset on Alcator C-Mod*
}

\author{
J. A. Baumgaertel \\ University of Washington, Seattle, WA, 98105 \\ M. H. Redi, R. V. Budny, D. C. McCune \\ Princeton Plasma Physics Laboratory, Princeton, NJ, 08543 \\ W. Dorland \\ University of Maryland, College Park, MD 20742 \\ C. L. Fiore \\ Massachusetts Institute of Technology, Cambridge, MA, 02139
}

Insight into microturbulence and transport in tokamak plasmas is being sought using linear simulations of drift waves near the onset time of an internal transport barrier (ITB) on Alcator CMod. Microturbulence is likely generated by instabilities of drift waves and causes transport of heat and particles. This transport is studied because the containment of heat and particles is important for the achievement of practical nuclear fusion. We investigate nearness to marginal stability of ion temperature gradient (ITG) modes for conditions in the ITB region at the trigger time for ITB formation. Data from C-Mod, analyzed by TRANSP (a time dependent transport analysis code), is read by the code TRXPL and made into input files for the parallel gyrokinetic model code GS2. Temperature and density gradients in these input files are modified to produce new input files. Results from these simulations show a weak ITG instability in the barr ier region at the time of onset, above marginal stability; the normalized critical temperature gradient is $80 \%$ of the experimental temperature gradient. The growth rate increases linearly above the critical value, with the spectrum of ITG modes remaining parabolic up to a multiplicative factor of 2 . The effect of varying density gradients is found to be much weaker and causes the fastest growing drift mode to change from ITG to trapped electron mode character. Simulations were carried out on the NERSC IBM 6000 SP using 4 nodes, 16 processors per node. Predictive simulations were examined for converged instability after 10,000-50,000 timesteps in each case. Each simulation took approximately 30 minutes to complete on the IBM SP. 


\section{Introduction}

Insight into microturbulence and transport in tokamak plasmas is being sought using linear simulations of drift waves near the onset time of an internal transport barrier (ITB) on Alcator C-Mod [1]. Microturbulence is widely believed to be generated by drift wave instabilities causing transport of heat and particles. This transport is studied because the containment of heat and particles is important for the achievement of practical nuclear fusion. If transport was better understood, then it would be possible to design a better fusion reactor.

An ITB is a location in the plasma at which there is a sharp decrease in the density and/or temperature profiles, indicating that little plasma or heat is being transported through this region. Anything that reaches the plasma core will most likely stay in the core. Thus, the ITB region has good confinement. The microstability studies were undertaken to learn about the conditions in the plasma just before ITB formation, for possible ITB control.

A drift wave is an oscillation of plasma particle densities and currents and their electrostatic and electromagnetic fields. They are caused by particle drifts due to the electric $(\vec{E})$ and magnetic ( $\vec{B}$ ) fields in the tokamak plasma, such as the $\vec{E} \times \vec{B}$ drift of particles (Ref. [2], chapter 2). Charged particles move in a helical fashion around magnetic field lines, and in the presence of an electric field, they drift out of their helical orbits in a direction perpendicular to both $\vec{E}$ and $\dot{B}$. Drifts can also arise from curvature of magnetic field lines and magnetic field gradients.

Components of the microturbulent electrostatic and electromagnetic fields may be written as $\left\{S(k, \omega) e^{i(k x-? t)}\right\}$, each mode described by frequencies, $\omega$, and wave vectors, $\vec{k} \cdot k_{\perp}$ is perpendicular to the magnetic field line which wraps around a magnetic flux surface. Further details about drift wave physics may be found in reference [2], chapter 8 . 
Three types of drift waves are believed to affect plasma confinement: the ion temperature gradient (ITG) mode, the trapped electron mode (TEM), and the electron temperature gadient (ETG) mode. The normalized wave vectors, $k_{\perp} \rho_{s}$, of the ITG are in the range $k_{\perp} \rho_{s} \sim 0.1-0.8$; of the TEM, $k_{\perp} \rho_{s} \sim 1-8$; and of the ETG, $k_{\perp} \rho_{s} \sim 10-80$, where $\rho_{s} \equiv \frac{\sqrt{m_{i} T_{e}}}{e B}$. Because the ITG mode has the longest wavelength, it is most dangerous for causing plasma transport; such instabilities could cause a loss of heat or plasma on a larger scale than would the shorter wavelength modes. Therefore, we wish to see if our experiment is above or below marginal stability of the ITG, and determine the critical temperature gradient so as to compare with standard models used in reactor design.

The experiment being studied is an off-axis radio frequency (RF) heated H-mode which develops an ITB near the time of 0.9 seconds (Figs. 1-4) [3]. The ITB forms at a radius for which the ratio to the minor radius is $r / a \cong 0.45$. All of the simulations are based on data taken at the ITB trigger time, 0.9 seconds. Table I shows plasma parameters for the experiment.

\section{Materials and Methods}

To investigate the drift wave microturbulence, linear simulations of drift wave stability were carried out using the massively parallel code GS2 [4]. The time dependent transport analysis code TRANSP [5] was used to analyze data from C-Mod and TRXPL was used to create GS2 input files from the TRANSP output. These input files contain such information as the plasma equilibrium configuration, the plasma location of interest, and parameters for each of the plasma species, including density, temperature, gradients of the density and temperature, and collisionalities. The C-Mod plasma was modeled with four species: electrons, deuterons, boron 
ions, and trace amounts of hydrogen ions. The boron and hydrogen ions are present as impurities in the plasma.

GS2 solves the perturbed distribution function of the plasma particles, given by

$$
f=f_{0}+\left[e_{j} \phi \frac{\partial f_{0}}{\partial K}+g \exp \left(i \frac{\mathbf{v}_{\perp} \times \mathbf{b} \cdot \mathbf{k}_{\perp}}{\omega_{c j}}\right)\right],
$$

where $g(\mu, K, x)$ satisfies the gyrokinetic equation:

(2) $\frac{\partial g}{\partial t}+\mathrm{v}_{\|} \mathbf{b} \cdot \nabla g+i \mathbf{k}_{\perp} \cdot \mathbf{v}_{g} g=-\left[\omega \frac{\partial f_{0}}{\partial K}-\frac{\mathbf{b} \times \nabla f_{0} \cdot \mathbf{k}_{\perp}}{\omega_{c j}}\right]\left[J_{0}(z) e_{j}\left(\phi-\mathrm{v}_{\|} A_{\|}\right)+\frac{2 J_{1}(z)}{z} \mu B_{\|}\right]$.

$\mathrm{K}$ is the kinetic energy of the particles, $\phi$ and $A_{\|}$are perturbed potentials, $\mathbf{b}=\mathbf{B} /|\mathbf{B}|, e_{j}$ is the charge of the particle $j, \omega_{c j}=e_{j} B / m_{j}$ is the cyclotron frequency of particle $j, J_{0}(z)$ and $J_{1}(z)$ are Bessel functions, $\mathrm{v}_{\|}$and $\mathrm{v}_{\perp}$ are components of the particle velocity, $k_{\perp}$ is the perpendicular wave vector (inversely proportional to the wavelength of the drift wave), $v_{g}$ is the guiding center velocity, and $z=k_{\perp} \mathrm{v}_{\perp} / \omega_{c j}$ (reference [2], chapter 2).

The simulations were carried out on the Department of Energy National Energy Research Scientific Computing Center's (NERSC) IBM 6000 SP, nicknamed Seaborg. Hundreds of linear stability simulations were carried out, scaling normalized density and temperature gradients for each case. Each simulation used 4 nodes, 16 processors per node and took approximately 30 minutes to complete on the IBM SP.

GS2 simulations yield growth rates, $\gamma$, and real frequencies, $\omega$, for each wave vector of the simulated drift wave. These values were examined for converged instability (positive $\gamma$ and corresponding $\omega$ ) after 10,000-50,000 timesteps in each case, and plotted with EXCEL GS2 also calculates eigenfunctions of the electrostatic and electromagnetic fields for each wave vector. 


\section{Results}

\section{A. Instabilities in Three Regions of the Plasma}

For each run, EXCEL was used to plot the growth rates and real frequencies as functions of normalized wave vectors, $k_{\perp} \rho_{s}$. Wave vectors, which correspond to the ITG, TEM, and ETG mode drift waves, were plotted for three locations in the plasma: the plasma core, the ITB region, and outside the ITB. Negative growth rates denote damped modes $\left(e^{-\gamma t}\right)$ and are set to zero in the plots. Figures 5 and 7 show the growth rates, $\gamma$, and the frequencies, $\omega$, as a function of wave vector, $k_{\perp} \rho_{s}$, for all three drift wave mode ranges, while Figure 6 shows $\gamma$ for only the ITG range of $k_{\perp} \rho_{s}$ [6]. It was found that there are positive growth rates for ITG and ETG modes at and outside the ITB, but no strongly unstable modes inside the plasma core. The real frequencies describe the mode rotation direction around the field line and are typically positive when the drift wave is an ITG mode, and negative for TEM and ETG modes.

\section{B. At the ITB Region: Temperature Gradient Scaling}

Next, the ITG range of wave vectors at the ITB region was considered and the normalized temperature gradients ( $a \nabla T / T$, Table I) of all the plasma species were scaled in order to obtain the dependence of growth rate on temperature gradient. The gradient was varied by factors of 0.1 to 10 . Figure 8 shows $\gamma$ versus $k_{\perp} \rho_{s}$ for each case. From this, the maximum growth rate for each case was plotted as a function of the scaling factor on the normalized temperature gradient (Fig. 10). The real frequencies, $\omega$, versus $k_{\perp} \rho_{s}$ are shown in Figure 9, and the real frequency corresponding to the maximum growth rate per run is plotted as a function of scaling factor in Figure 11. 


\section{At the ITB Region: Density Gradient Scaling}

Next, the normalized density gradients $(a \nabla n / n$, Table I) of all the plasma species were scaled to examine the ITG growth rate dependence on normalized density gradient. The scaling factors of the density gradient ranged from $1 / 6$ to 10 . Figures 12 and 13 shows $\gamma$ and $\omega$ versus $k_{\perp} \rho_{s}$ and Figures 14 and 15 show the maximum $\gamma$ and the corresponding $\omega$ as functions of the scaling factor of the density gradients.

\section{Discussion and Conclusions}

\section{A. Instabilities in Three Regions of the Plasma}

GS2 solutions of the gyrokinetic equation were examined for drift wave instability, that is, a positive growth rate. If the simulated modes are stable, then no transport would be driven by these modes. All drift wave modes were stable in the plasma core $[6,7]$ (Fig. 5). In the ITB region, however, the ITG is unstable, which could cause some transport of heat and particles. However, Figure 5 shows that the ITG instability in the barrier region is significantly weaker than that found outside the ITB. This is likely the cause of the developing good confinement (i.e., lack of transport) within the barrier region. There are also strong ETG instabilities both at and outside of the ITB, but because the ETG has the shortest wavelengths of the drift wave modes, it is unlikely that it will have much effect on ion transport. ETG is thought to be important in heat transport mediated by electrons.

\section{B. At the ITB Region: Temperature Gradient Scaling}

Figure 10 indicates that at small normalized temperature gradients, the ITG is stable in the ITB region until the temperature gradient reaches a critical value, then it becomes approximately linearly unstable. The bump in the linear region of the graph, which corresponds to the dip in Figure 11, is due to the fact that the value of $k_{\perp} \rho_{s}$ at which the maximum growth 
rate occurs changes from 0.2 to 0.3 , as can be seen in Figure 8 . The simulations' critical temperature gradient is 0.80 of the experimental value. Thus, the experiment is well above marginal stability; recall that the ITG was found to be unstable in this region (Fig. 6).

\section{At the ITB Region: Density Gradient Scaling}

The GS2 simulations showed that the ITG growth rates cannot be made zero in the barrier region by scaling the normalized density gradients (Fig. 14). The growth rate has a relatively weak dependence on normalized density gradient- the experimental gradient had to be scaled by a factor of ten to increase the growth rate by a factor of about nine, as opposed to the temperature gradient, which only had to be scaled by a factor of two to increase the growth rate by a factor of eight.

There is a transition in the character of the most unstable ITG range drift waves as the normalized density gradient increases. Compare the real frequencies as a function of scaling factor in Figure 15 with the real frequencies for our base cases of ITG, TEM, and ETG modes in Figure 7. The most unstable drift wave starts as an ITG mode, but then shifts to a TEM mode at about 6.5 times the normalized experimental density gradient, as seen by the real frequency becoming negative and a development of discontinuity in the slope of the growth rate. This is to be expected from the stability diagram in Figure 16, showing the effects of the temperature and density gradients on drift wave instability [8]. A high enough shift in the normalized density gradient changes the mode from ITG-like to TEM-like.

Much of the study described here will appear in a forthcoming publication [7].

\section{Future Research}

Many lines of future research would be interesting. For example, future research could include investigation of marginal stability conditions in the plasma core and outside the ITB 
region, as well as the effect on the critical temperature of density and temperature perturbations for each species separately. Critical gradients can be compared to standard models [9]. In addition, nonlinear ITG studies in the barrier region would deepen our understanding of ITB formation; shifts in critical temperatures have been found from nonlinear microturbulence studies[10].

\section{Acknowledgements}

We would like to thank the U.S. Department of Energy and the Princeton Plasma Physics Laboratory for the opportunity to participate in the SULI program. We thank James Morgan for his enthusiastic and energetic work with the SULI students, and the Alcator C-Mod group at MIT for the data and analysis of the experiment. Work also supported by U. S. DOE Contract DEAC02-76CH03073. 


\section{References}

* Prepared in partial fulfillment of the requirements of the Office of Sc ience, Department of Energy's Science Undergraduate Laboratory Internship under the direction of Dr. M. H. Redi at the Princeton Plasma Physics Laboratory.

[1] I. H. Hutchinson, R. L. Boivin, F. Bombarda et al., Phys. Plas. 1, 1511 (1994).

[2] J. A. Wesson, Tokamaks, Oxford University Press, New York, NY (1997).

[3] C. L. Fiore, et. al. Phys. Plas. 8, 2023 (2001).

[4] M. Kotschenreuther, et. al., Comp.Phys. Com. 88, 128 (1995).

[5] R. J. Hawryluk, in Physics of Plasmas Close to Thermonuclear Conditions, edited by B. Coppi, G. G. Leotta, D. Pfirsch, R. Pozzoli, and E. Sindoni (Pergamon, Oxford, 1980), Vol. 1, p. 19.

[6] M. H. Redi, et. al. EPS-2004, London, UK, paper P2-163.

[7] M. H. Redi , et. al. "Stability of microturbulent drift modes during internal transport barrier formation in the Alcator C-Mod radio frequency heated H-mode", in preparation.

[8] X. Garbet, P. Mantica, C. Angioni, et al., "Physics of Transport in Tokamaks", to appear in Proceedings of the 31th EPS Conference on Plasma Physics and Controlled Fusion, London, England (2004), and Plasma Physics and Controlled Fusion (2005).

[9] F. Jenko, W. Dorland, G. W. Hammett, Phys. Plas. 8, 4096 (2001).

[10] A. M. Dimits, G. Bateman, M. A. Beer et al., Phys. Plasmas 7, 969 (2000). 
Table I. Plasma parameters for C-Mod simulations at $0.9 \mathrm{sec}$. The ratios of densities are: $\mathrm{n}_{\mathrm{d}} / \mathrm{n}_{\mathrm{e}}=$ $0.8, \mathrm{n}_{\mathrm{b}} / \mathrm{n}_{\mathrm{e}}=0.03, \mathrm{n}_{\mathrm{h}} / \mathrm{n}_{\mathrm{e}}=0.04$, and $a_{r e f}=0.22 \mathrm{~m}$.

\begin{tabular}{|c|c|c|c|}
\hline Parameter & $r / a \sim 0.25$ & 0.45 & 0.65 \\
\hline$q$ & 0.99 & 1.32 & 2.00 \\
\hline$\hat{S}$ & 0.51 & 0.96 & 1.48 \\
\hline$T_{d} / T_{e}=T_{b} / T_{e}$ & 0.99 & 1.16 & 1.06 \\
\hline$T_{h} / T_{e}$ & 1.30 & 3.96 & 1.59 \\
\hline$-a_{r e f} \nabla n_{e} / n_{e}=-a_{r e f} \nabla n_{s} / n_{s}$ & 0.71 & 0.42 & 0.04 \\
\hline$-a_{r e f} \nabla T_{e} / T_{e}$ & 1.47 & 2.35 & 2.83 \\
\hline$-a_{r e f} \nabla T_{d} / T_{d=-a_{r e f}} \nabla T_{b} / T_{b}$ & 0.67 & 2.75 & 3.41 \\
\hline$-a_{r e f} \nabla T_{h} / T_{h}$ & -3.13 & 2.75 & 3.41 \\
\hline$v_{e} v_{d}$ & 29.9 & 38.4 & 33.3 \\
\hline$v_{b} / v_{d}$ & 7.12 & 7.12 & 7.12 \\
\hline$v_{h} / v_{d}$ & 1.10 & 0.30 & 0.93 \\
\hline$T_{r e f}(\mathrm{keV})=T_{e}$ & 1.15 & 0.77 & 0.45 \\
\hline$n_{r e f}=n_{e}\left(\mathrm{~m}^{-3}\right)$ & $3.1 \times 10^{20}$ & $2.8 \times 10^{20}$ & $2.7 \times 10^{20}$ \\
\hline$\beta_{r e f}$ & $0.75 \%$ & $0.45 \%$ & $0.25 \%$ \\
\hline Freq norm $=\left(T_{r e f} / m_{r e f}\right)^{0.5} / a_{r e f}\left(\sec ^{-1}\right)$ & $1.07 \times 10^{6}$ & $0.88 \times 10^{6}$ & $0.67 \times 10$ \\
\hline
\end{tabular}




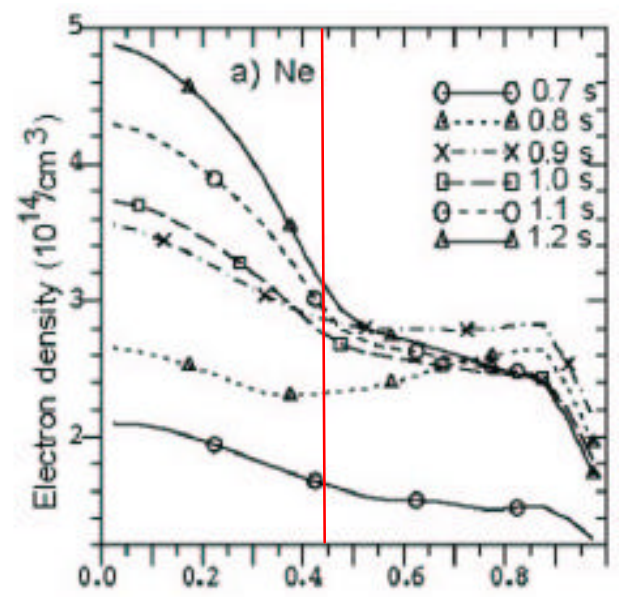

Figure 1. Electron density profile for the C-Mod experiment. Electron density for radial locations in the plasma, given in $r / a \equiv$ the radial distance, $r$, from plasma magnetic axis divided by the minor radius, $a$. Simulations were carried out at the ITB trigger time, 0.9 seconds; the ITB forms at $r / a \cong 0.45$. 

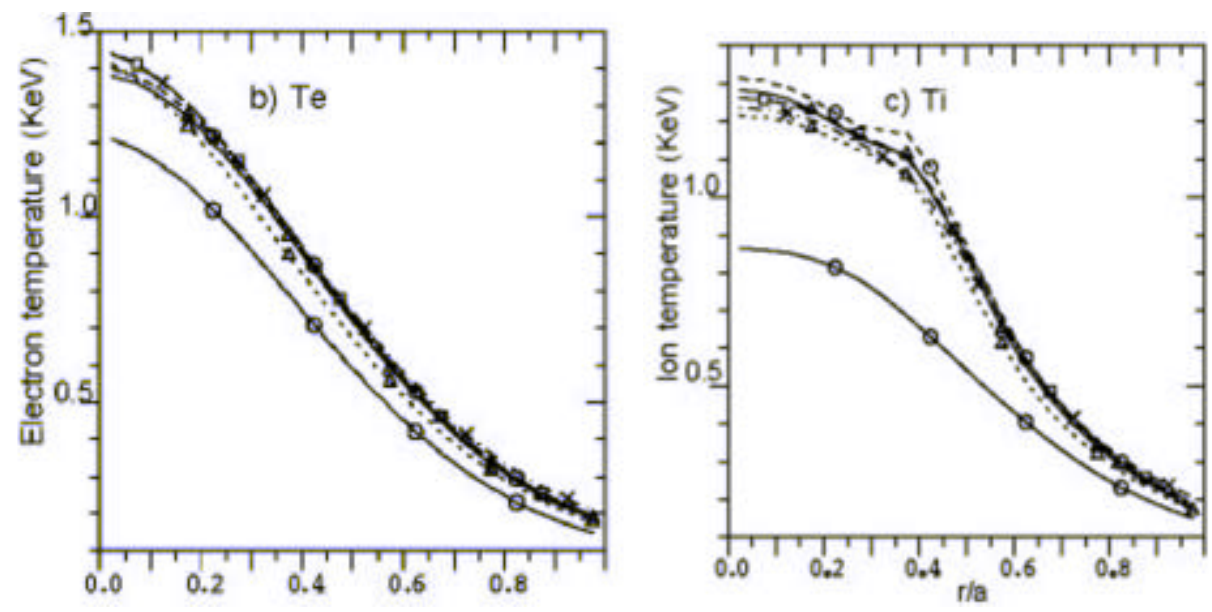

Figures 2. and 3. Temperature profiles for electrons and ions vs. $r / a$. Notice that the temperature profiles do not change much with time.

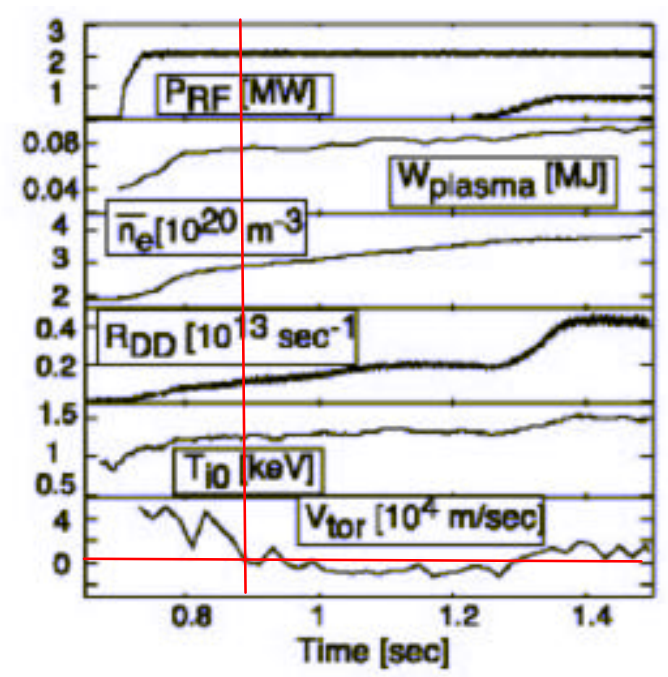

Figure 4. Time dependent behavior of some parameters for the C-Mod experiment. The plasma was heated initially with off-axis radio frequency (RF) heating; at 1.25 seconds on-axis RF heating is added. $W_{\text {Plasma }}$ is the stored energy of the plasma, $\bar{n}_{e}$ is line averaged electron density, $R_{D D}$ is the rate of production D-D of neutrons, $T_{i 0}$ is the ion temperature, and $\mathrm{v}_{\text {tor }}$ is the toroidal velocity (it goes through zero at the time of interest, 0.9 seconds). [Figure from S. Wukitch, R. L. Boivin, P. T. Bonoli, et al., Phys. Plas. 9, 2149 (2002), used with permission.] 


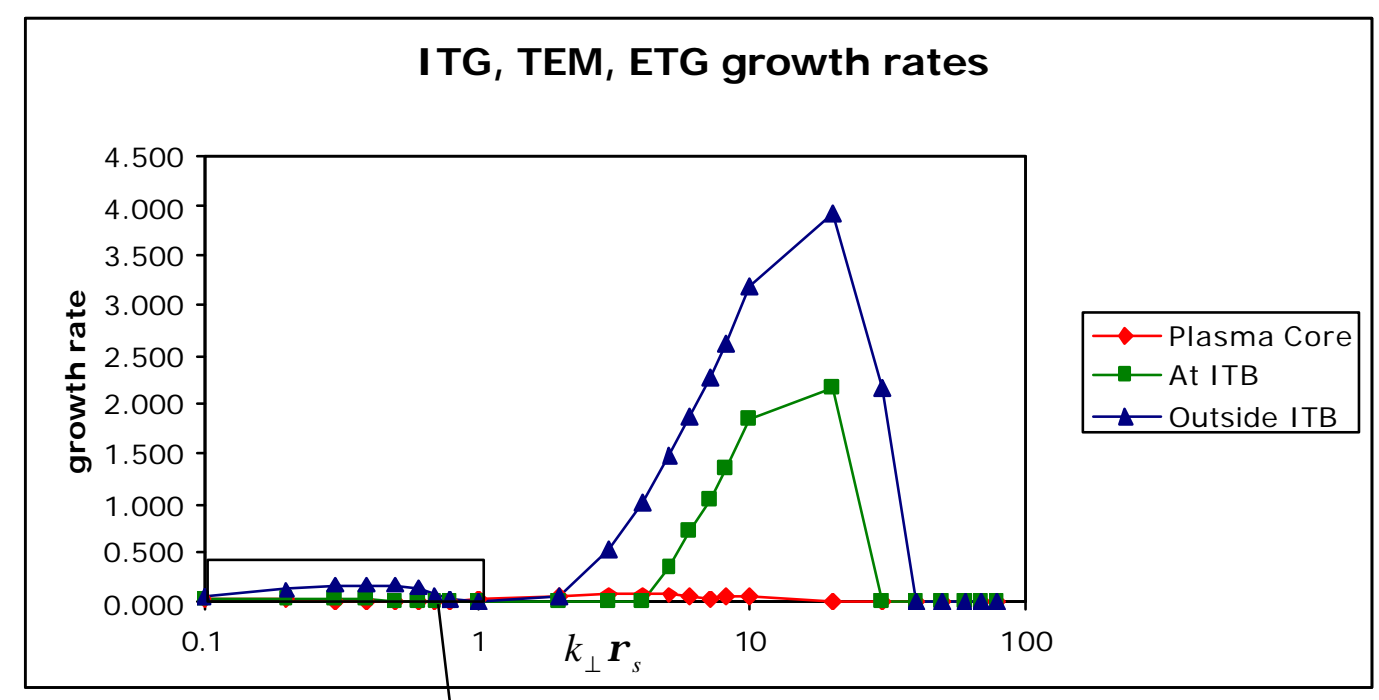

Figure 5. Growth rates of ITG, TEM, and ETG drift wave modes as a function of normalized wave vector, for the three regions of interest.

\section{ITG growth rates}

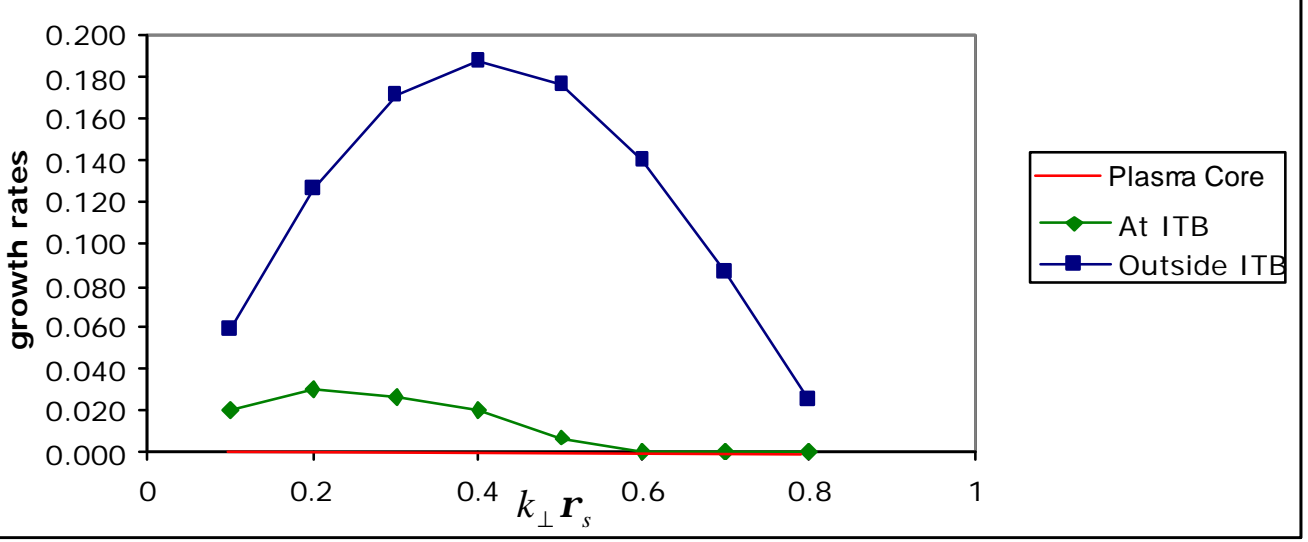

Figure 6. ITG growth rate as a function of normalized wave vector, for three regions in the plasma. 


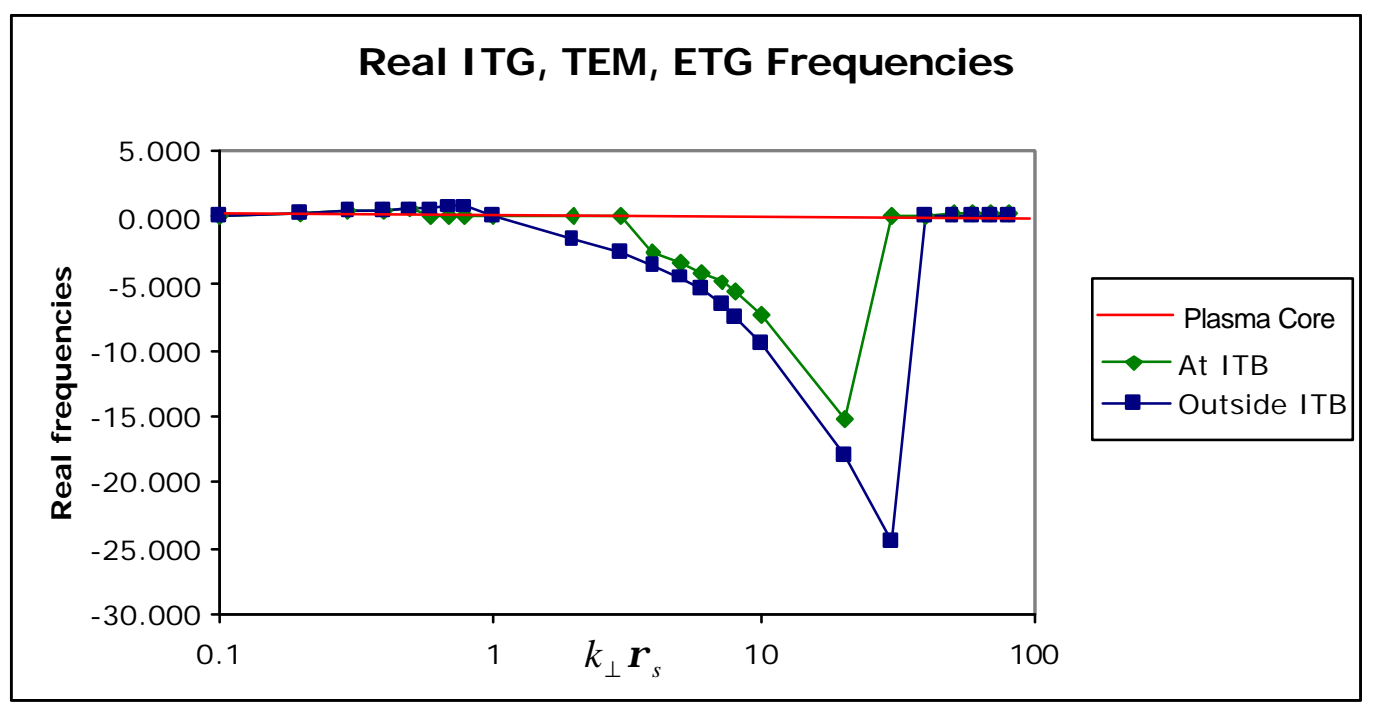

Figure 7. ITG, TEM, and ETG real frequencies as a function of normalized wave vectors at three regions in the plasma. 


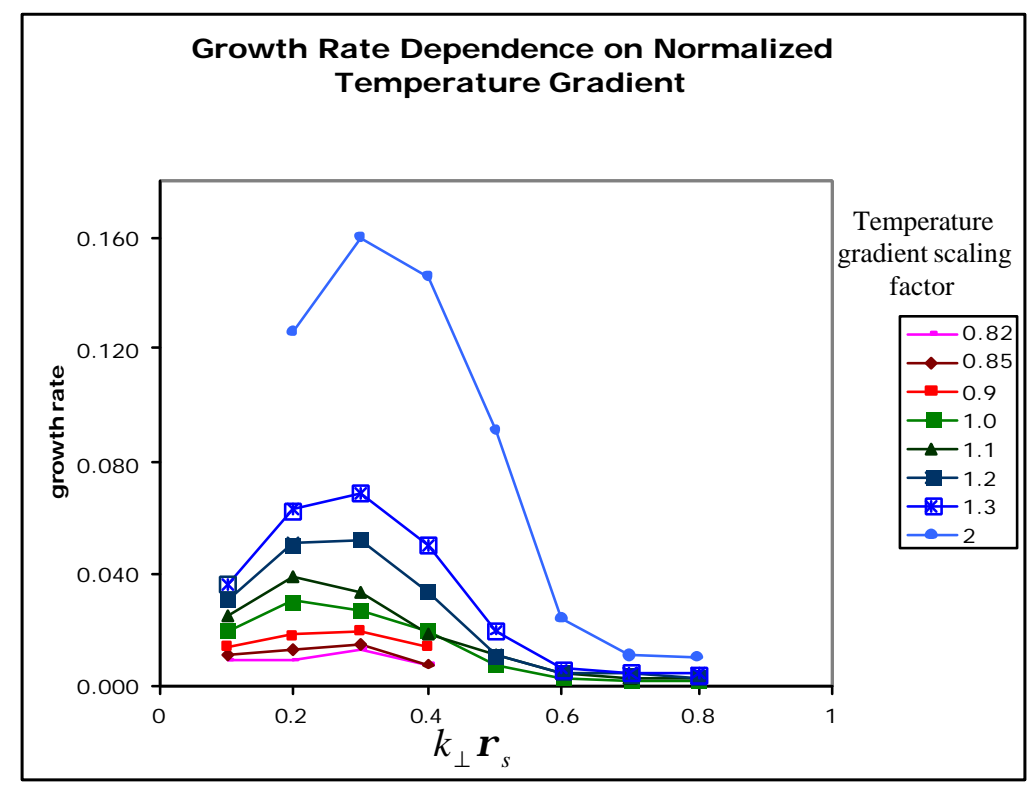

Figure 8. ITG growth rates at the ITB region.

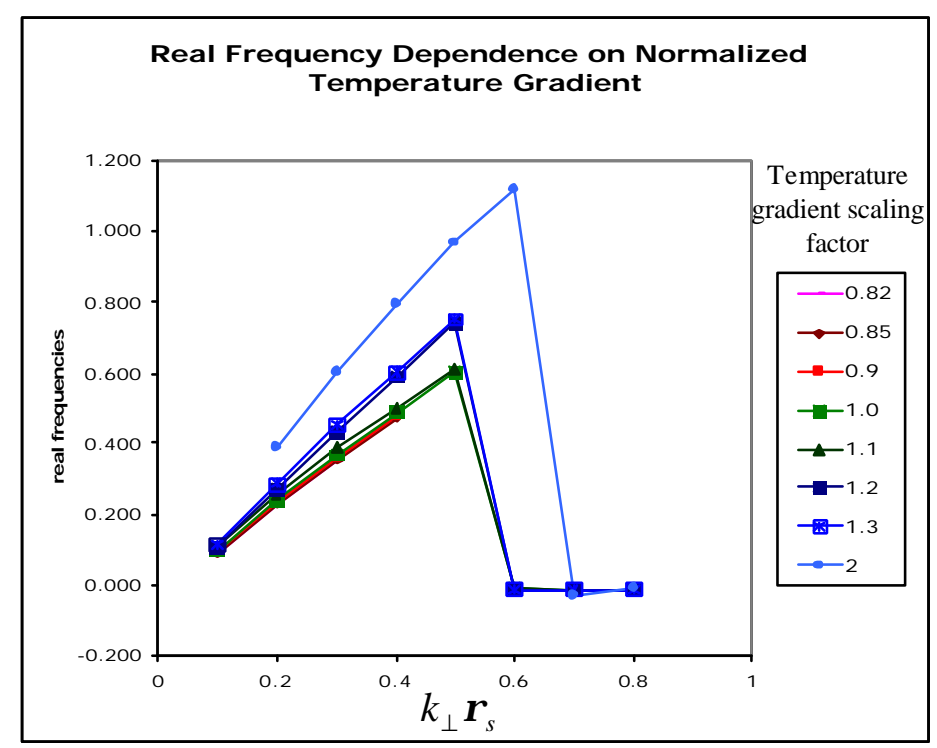

Figure 9. ITG real frequencies at the ITB region. 


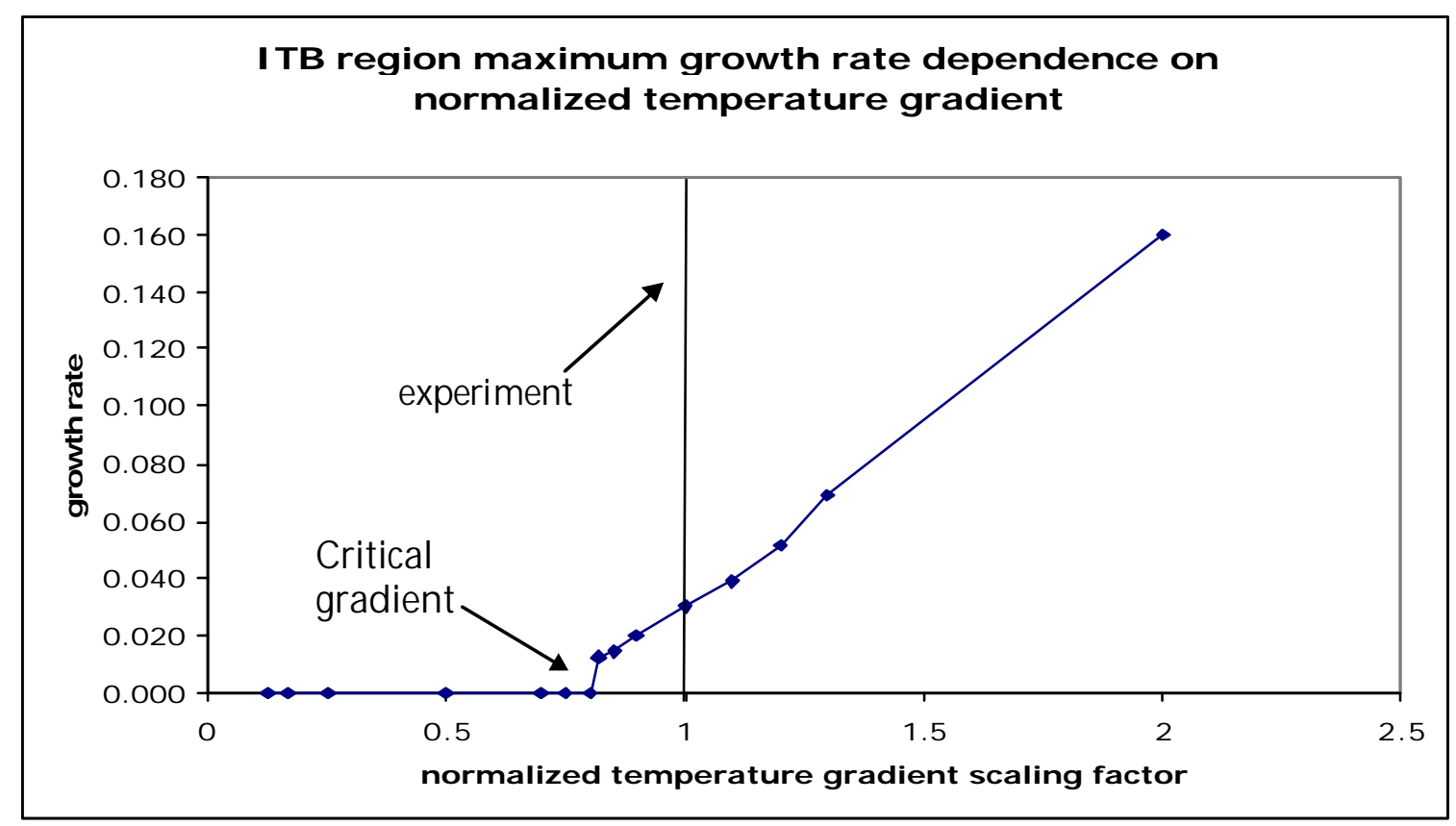

Figure 10. ITG growth rate as a function of normalized temperature gradient.

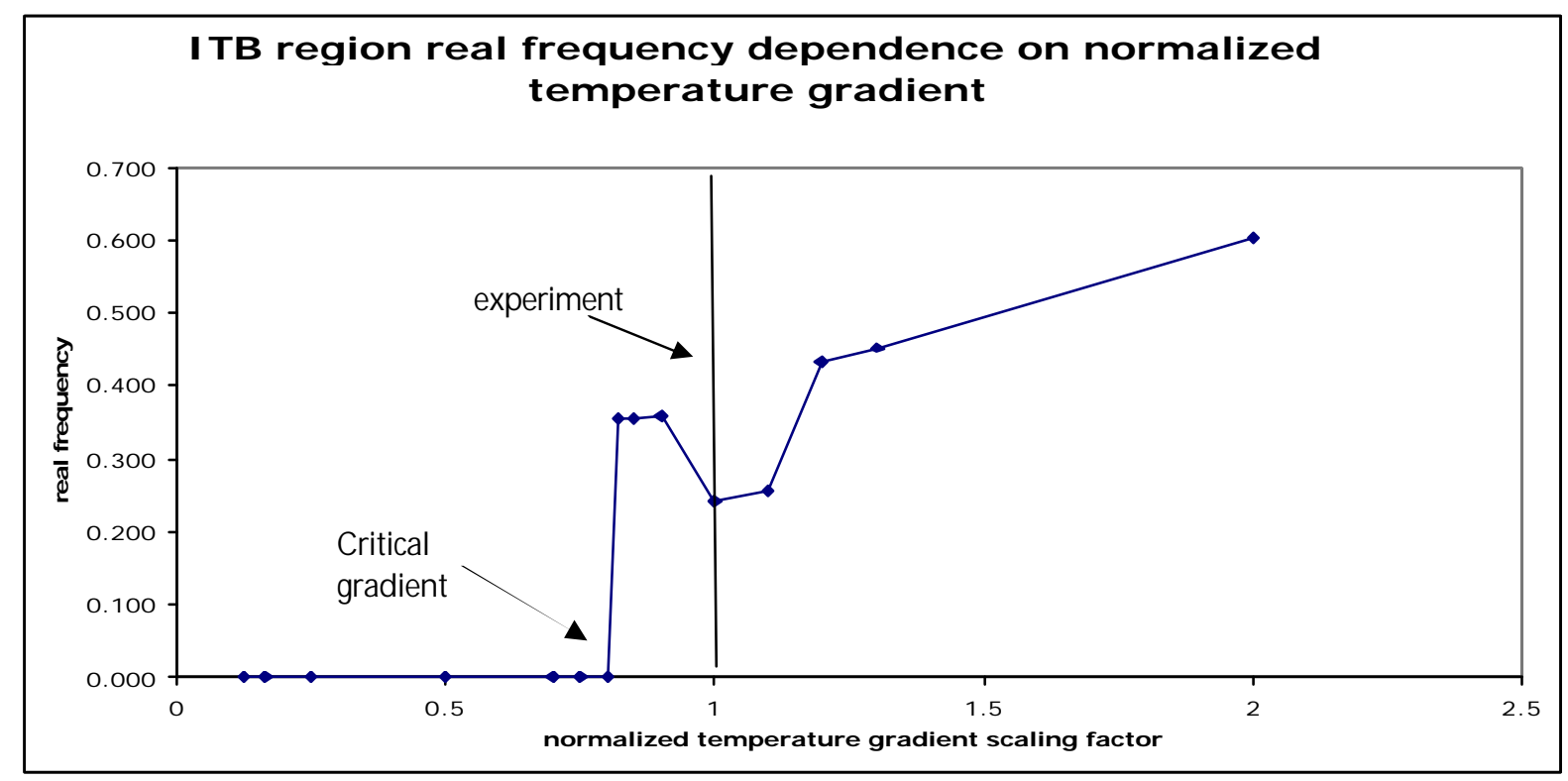

Figure 11. ITG real frequency as a function of normalized temperature gradient. 


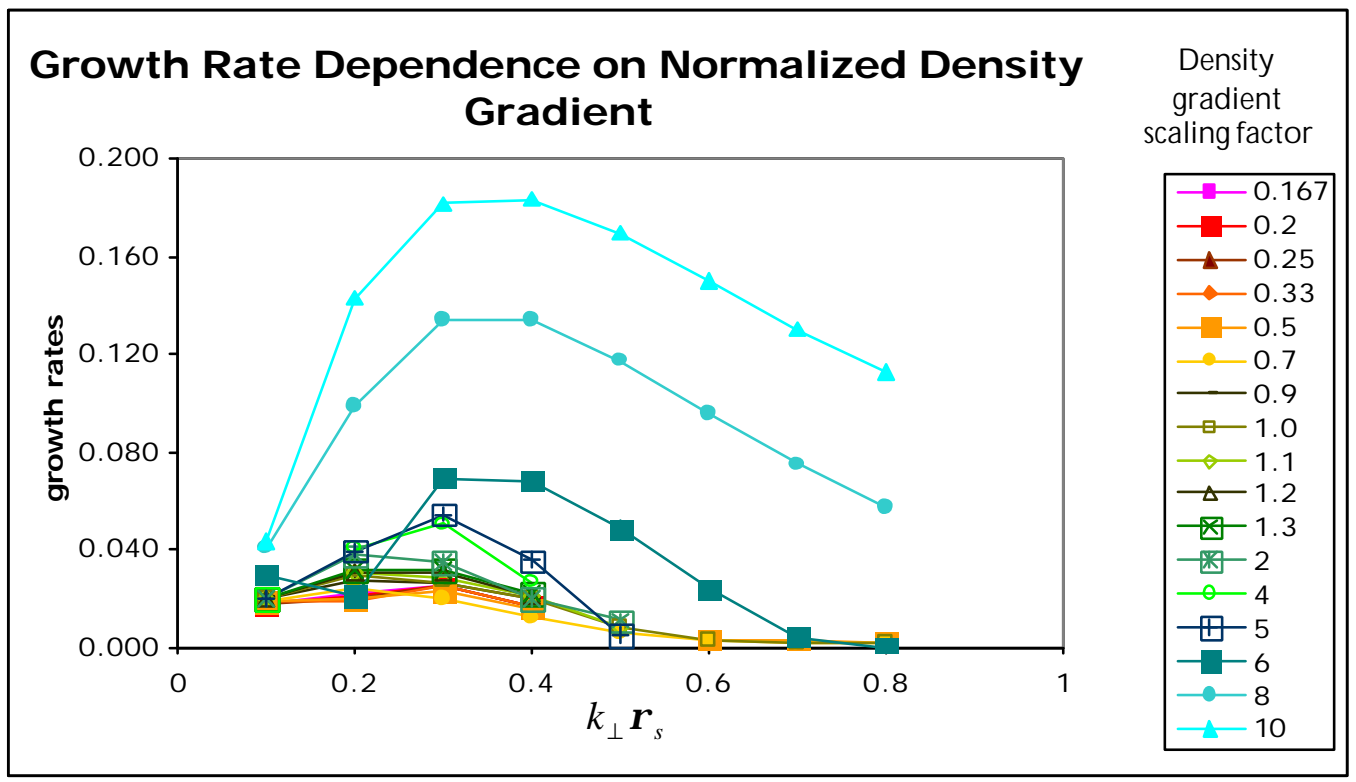

Figure 12. Drift wave mode growth rates at the ITB region.

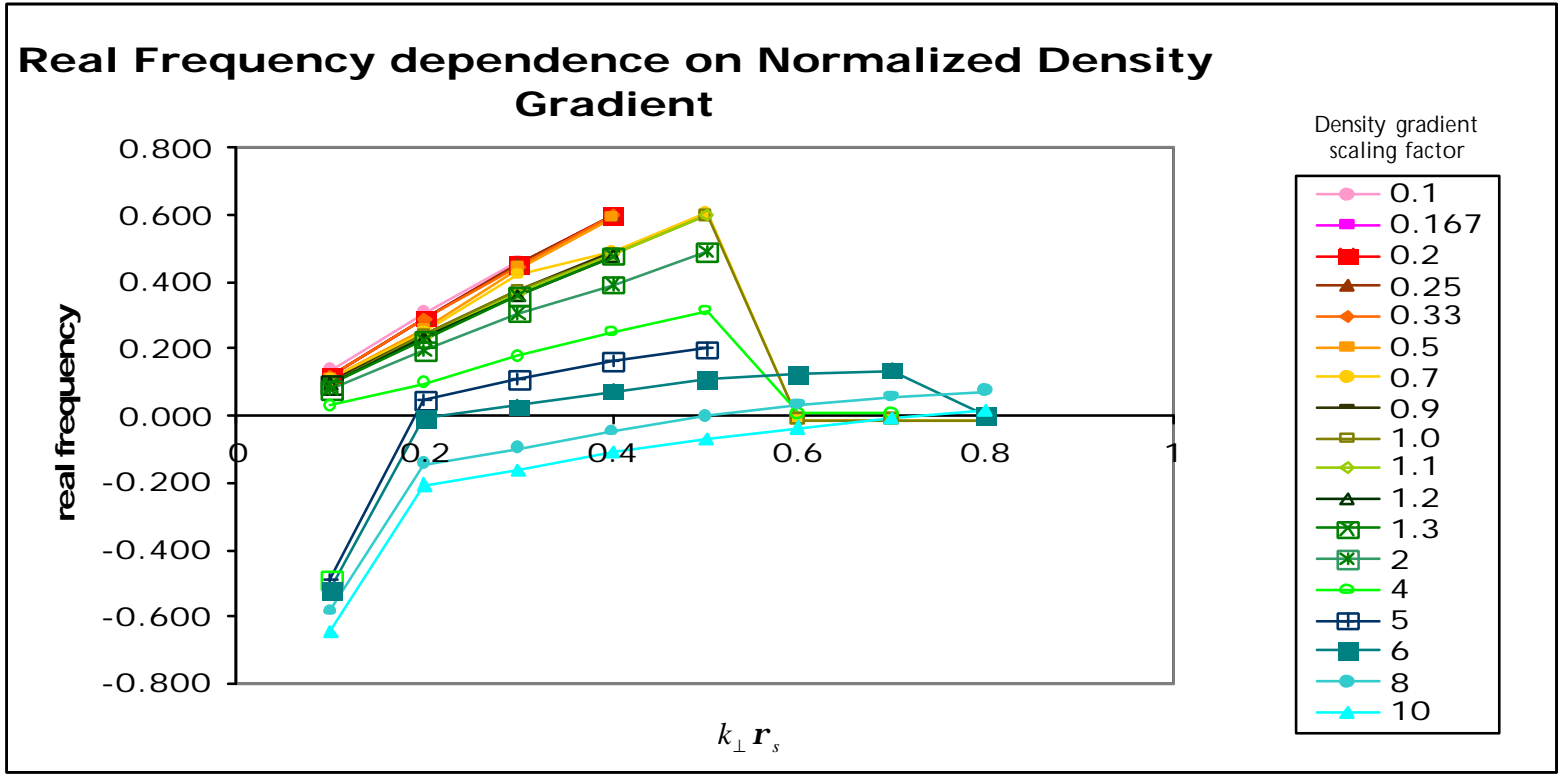

Figure 13. Drift wave mode real frequencies at the ITB region. 


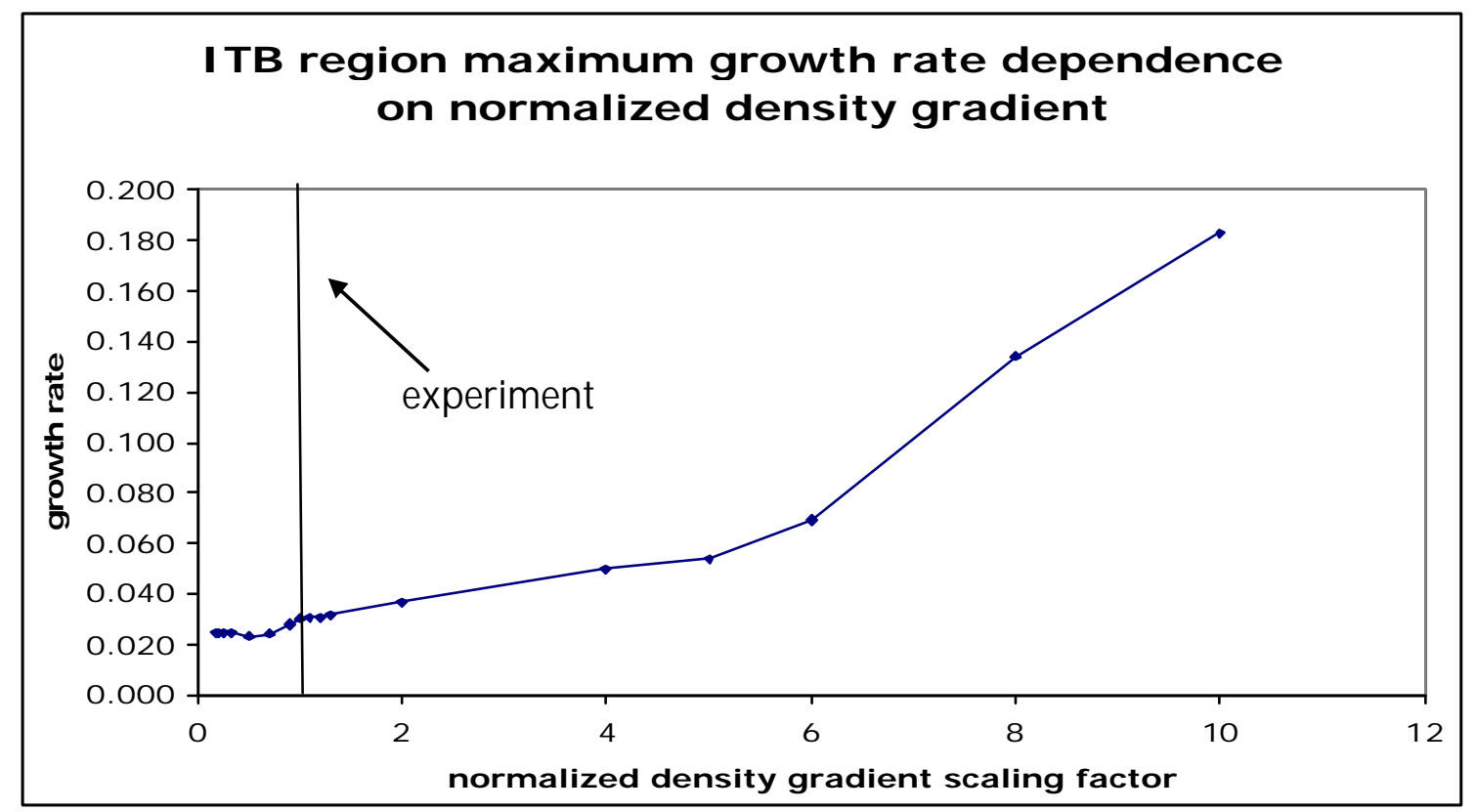

Figure 14. Drift wave mode growth rate as a function of normalized density gradient.

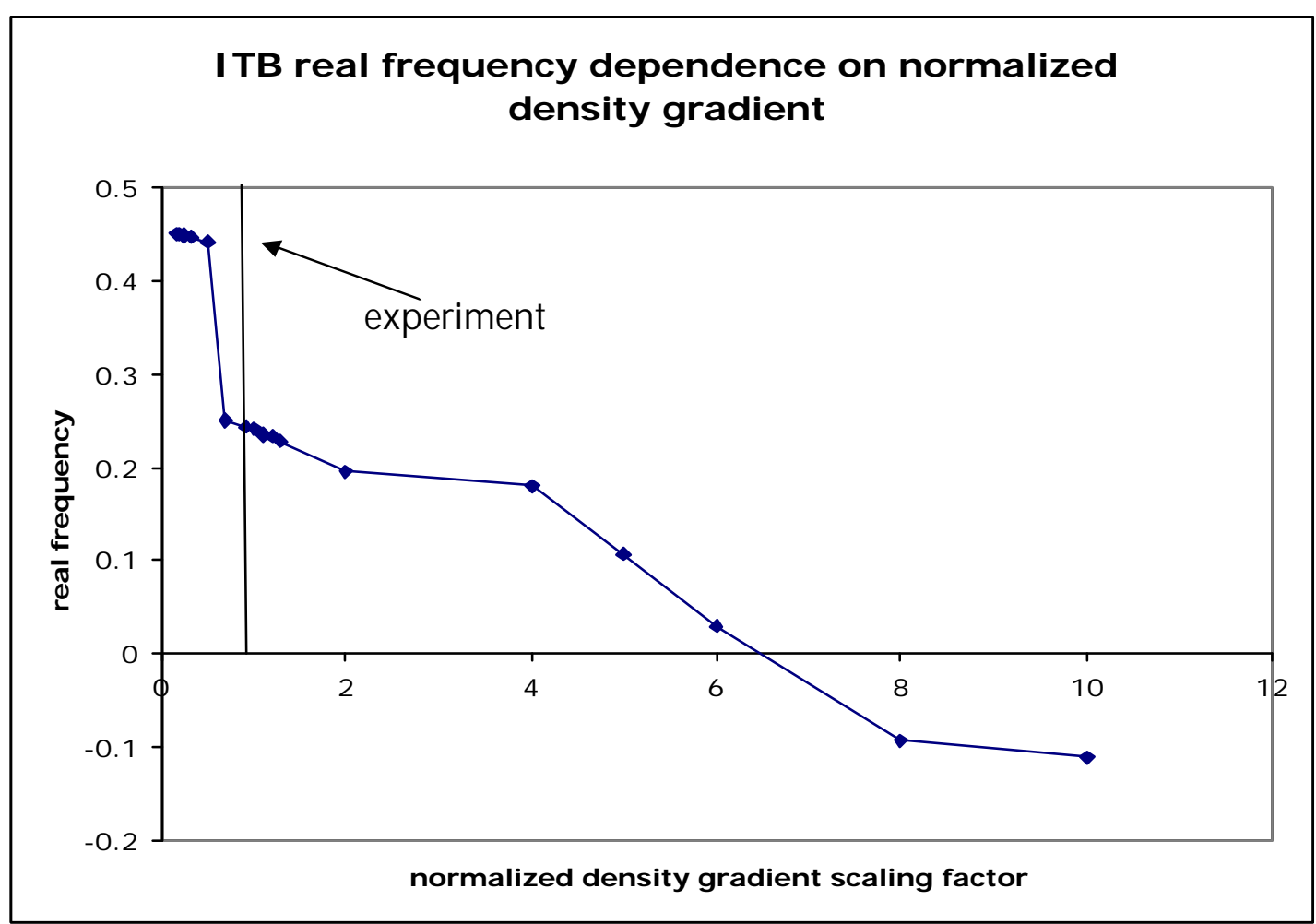

Figure 15. Drift wave mode real frequency as a function of normalized density gradient. 


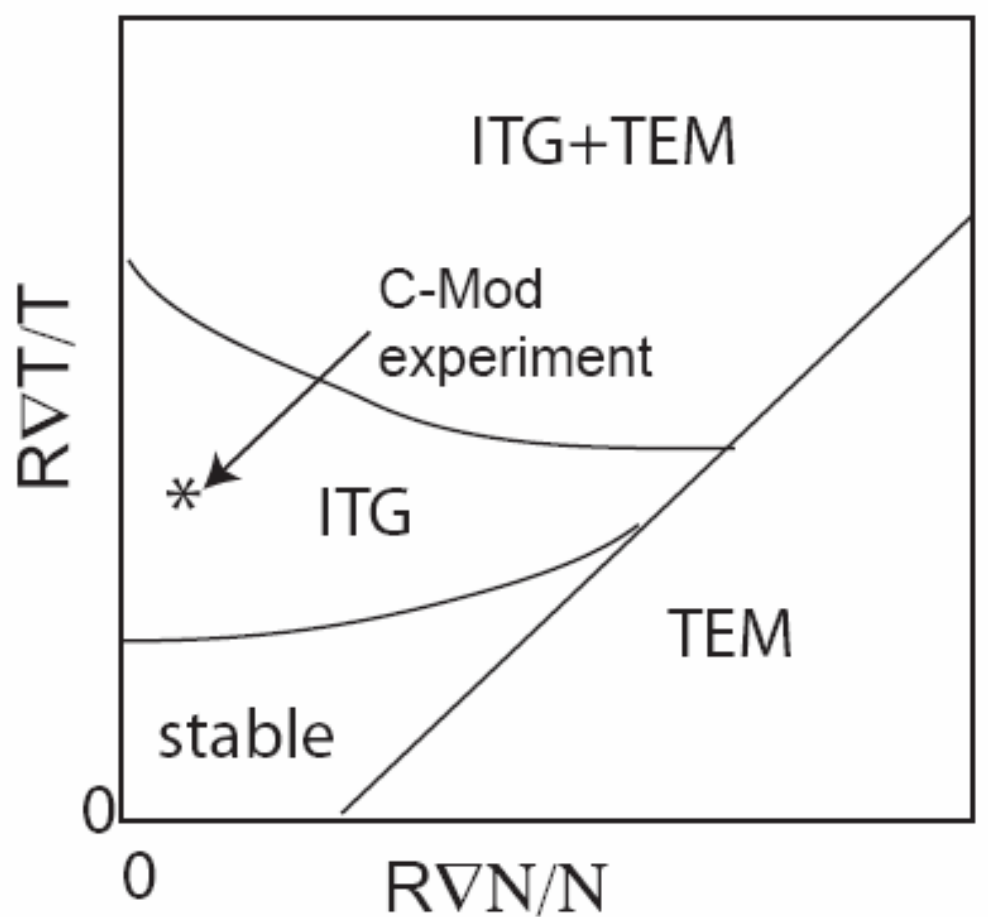

Figure 16. Stability diagram for ITG/TEM modes. Figure based on Fig. 1. of [8]. 



\section{External Distribution}

Plasma Research Laboratory, Australian National University, Australia

Professor I.R. Jones, Flinders University, Australia

Professor João Canalle, Instituto de Fisica DEQ/IF - UERJ, Brazil

Mr. Gerson O. Ludwig, Instituto Nacional de Pesquisas, Brazil

Dr. P.H. Sakanaka, Instituto Fisica, Brazil

The Librarian, Culham Laboratory, England

Mrs. S.A. Hutchinson, JET Library, England

Professor M.N. Bussac, Ecole Polytechnique, France

Librarian, Max-Planck-Institut für Plasmaphysik, Germany

Jolan Moldvai, Reports Library, Hungarian Academy of Sciences, Central Research Institute for Physics, Hungary

Dr. P. Kaw, Institute for Plasma Research, India

Ms. P.J. Pathak, Librarian, Institute for Plasma Research, India

Ms. Clelia De Palo, Associazione EURATOM-ENEA, Italy

Dr. G. Grosso, Instituto di Fisica del Plasma, Italy

Librarian, Naka Fusion Research Establishment, JAERI, Japan

Library, Laboratory for Complex Energy Processes, Institute for Advanced Study, Kyoto University, Japan

Research Information Center, National Institute for Fusion Science, Japan

Dr. O. Mitarai, Kyushu Tokai University, Japan

Dr. Jiangang Li, Institute of Plasma Physics, Chinese Academy of Sciences, People's Republic of China

Professor Yuping Huo, School of Physical Science and Technology, People's Republic of China

Library, Academia Sinica, Institute of Plasma Physics, People's Republic of China

Librarian, Institute of Physics, Chinese Academy of Sciences, People's Republic of China

Dr. S. Mirnov, TRINITI, Troitsk, Russian Federation, Russia

Dr. V.S. Strelkov, Kurchatov Institute, Russian Federation, Russia

Professor Peter Lukac, Katedra Fyziky Plazmy MFF UK, Mlynska dolina F-2, Komenskeho Univerzita, SK-842 15 Bratislava, Slovakia

Dr. G.S. Lee, Korea Basic Science Institute, South Korea

Institute for Plasma Research, University of Maryland, USA

Librarian, Fusion Energy Division, Oak Ridge National Laboratory, USA

Librarian, Institute of Fusion Studies, University of Texas, USA

Librarian, Magnetic Fusion Program, Lawrence Livermore National Laboratory, USA

Library, General Atomics, USA

Plasma Physics Group, Fusion Energy Research Program, University of California at San Diego, USA

Plasma Physics Library, Columbia University, USA

Alkesh Punjabi, Center for Fusion Research and Training, Hampton University, USA

Dr. W.M. Stacey, Fusion Research Center, Georgia Institute of Technology, USA

Dr. John Willis, U.S. Department of Energy, Office of Fusion Energy Sciences, USA

Mr. Paul H. Wright, Indianapolis, Indiana, USA 
The Princeton Plasma Physics Laboratory is operated by Princeton University under contract with the U.S. Department of Energy.

\author{
Information Services \\ Princeton Plasma Physics Laboratory \\ P.O. Box 451 \\ Princeton, NJ 08543
}

Phone: 609-243-2750

Fax: 609-243-2751

e-mail: pppl_info@pppl.gov

Internet Address: http://www.pppl.gov 